\title{
The diabesity health economic crisis - the size of the crisis in a European island state following a cross-sectional study
}

Sarah Cuschieri ${ }^{* *}$ D, Josanne Vassallo², Neville Calleja ${ }^{3}$, Nikolai Pace ${ }^{1}$, Janice Abela², Bader A. Ali², Fatemah Abdullah", Elizier Zahra ${ }^{5}$ and Julian Mamo ${ }^{3}$

\begin{abstract}
Background: Diabetes type 2 and obesity are well-established global epidemics and contributors to clinical, social and economic health burdens. The prevalence rates of these diseases are still on the rise among countries resulting in a corresponding public health burden. The Mediterranean island of Malta, known for it's high diabetes and obesity rates, provides a good fundamental basis to portray the economical health burden of these diseases.

Method: A recent randomised stratified representative cross-sectional survey conducted in Malta tackling diabetes, obesity and other determinants, was used to work out the population prevalence of these diseases. The cost burden of diabetes and obesity, based on published data, was incorporated to the established population prevalence rates, in order to estimate the Maltese economical burden. Projections to the year 2050 by a bottom-up prevalence based design were performed.
\end{abstract}

Results: One eight of the Maltese adults (25 to 64 years) suffered from diabetes out of which approximately 10,000 adults were unaware of the disease. Alarmingly, more than a third of the Maltese population suffer from obesity. The approximate health care costs (direct and indirect) for the diabetic adult population was of $€ 29,159,217$ $(€ 21,994,676$ - $€ 38,919,121)$ annually, amounting to $3.64 \%(2.75-4.875 \%)$ of the total health expenditure in Malta. The obesity cost burden was of $€ 23,732,781$ ( $€ 21,514,972-€ 26,049,204)$ annually contributing for $2.97 \%(2.69-3.26 \%)$ of the total health expenditure. The projected prevalence and costs for 2050 exhibited an estimated cost burden increase of $€ 33,751,487(€ 25,458,606-€ 45,048,473)$ for the diabetes mellitus population and $€ 46,532,294$ $(€ 42,183,889-€ 51,074,049)$ for the obese population. These projected cost burdens are expected to increase exponentially the total health care expenditure in Malta by 2050.

Conclusion: Having an understanding of the prevalence and the economic cost burden of diabetes and obesity within a country, along with projections of the expected burden will enable policy and public health officials to clearly visualize this growing problem. It also helps in establishing effective preventive strategies and screening programs targeting these epidemics.

Keywords: Economic burden of disease, Burden of illness, Diabetes mellitus, Obesity, Malta

\footnotetext{
* Correspondence: sarah.cuschieri@um.edu.mt

${ }^{1}$ Department of Anatomy, Faculty of Medicine and Surgery, Biomedical

Building, University of Malta, Msida MSD 2080, Malta

Full list of author information is available at the end of the article
} 


\section{Background}

The global obesity and diabetes mellitus type 2 prevalence rates have increased exponentially over recent years [1, 2]. Globally an estimated 2 billion people are overweight, a third of which being obese [1]. The increasing prevalence of obesity is predicted to lead to other chronic related diseases [3]. The link between obesity and type 2 diabetes is well established through the development of obesity related insulin resistance. It follows that the prevalence of the two diseases is directly proportional [3]. However, only about 20-25\% of the overweight and obese population is expected to develop diabetes [4]. Both diseases lead to heavy increases in clinical, social and economic health burdens as well as to increments in morbidity and mortality $[5,6]$. They also impact on employment and productivity, both of which have significant direct impacts on a country's productivity and economical growth [7].

Malta is a European island nation in the middle of the Mediterranean Sea with a total population of 425,384 (median age 40.9 years). Its history is littered with diverse dominating powers and shifts in its culture throughout the centuries. Up to 150 years ago, the population followed a Mediterranean lifestyle and diet, although this has now shifted to a more Westernized lifestyle and diet [8]. The World Health Organization (WHO) conducted the last Maltese national prevalence study in Diabetes in 1981 [9]. Subsequently, a health examination pilot study was conducted on the Island in 2010. However, the latter study had a small sample size $(n=221)$ and offered only a glimpse of the actual diabetes and obesity burden [10]. This has led to Maltese policies and economic burden extrapolations being based on outdated sources, despite strong emigrational, cultural and lifestyle changes over recent decades [8]. Between 2014 and 2016, the University of Malta "SAHHTEK" (Your Health) cross-sectional study was conducted. This provided valid, updated prevalence rates, through which the diabetes mellitus type 2 and obesity health burden in Malta could be established. The aim of this study was to establish the current (for 2016) prevalence and economic burden of diabetes type 2 and obesity in Malta. The objectives were: 1) to establish the body mass distribution within the diabetic sub-population by age and gender; 2) to estimate the projected total population prevalence of type 2 diabetes and obesity in Malta for 2050; 3) estimate the economic burden of diabetes and obesity for the year 2050 and; 4) provide evidence based data for policy makers to target and implement prevention strategies concerning these non-communicable diseases. This study will serve as a fundamental basis for the burden estimation in neighbouring Mediterranean countries.

\section{Method}

A cross-sectional health examination survey was conducted between November 2014 and January 2016. The sample population was obtained from the national registry after performing randomization and stratification of the data by age (18 to 70 years) and gender [11]. The data was further stratified according to residence locality, to represent an approximate $1 \%$ population from each Maltese town. The total randomized and stratified population $(n=4,000)$ was invited to participate in a health examination survey set up in every Maltese town through an invitation letter sent out via post. The health examination survey consisted of a validated questionnaire and health examination including weight and height as well as blood letting for fasting blood glucose and lipid profile.

The measured weight and height was used to calculate the body mass index (BMI) by dividing the weight (in kilograms $-\mathrm{kg}$ ) over the height squared (meters squared $-\mathrm{m}^{2}$ ). Those participants with a BMI $<24.99 \mathrm{Kg} / \mathrm{m}^{2}$ were considered as normal BMI; $25-29.99 \mathrm{Kg} / \mathrm{m}^{2}$ as overweight and $>30 \mathrm{Kg} / \mathrm{m}^{2}$ as obese [12]. Participants were considered as suffering from 'previously known diabetes mellitus' if they gave a medical history of diabetes or were on oral hypoglycemic agents, irrelevant of the measured fasting blood glucose. Meanwhile, all those obtaining measured fasting blood glucose above $7 \mathrm{mmol} / \mathrm{L}$ were considered as newly diagnosed diabetics [13].

The diabetes population (total) was defined as the sum of the previously known diabetes mellitus participants to the newly diagnosed participants. Prevalence rates of diabetes (by gender and 10-year age groups) were calculated by dividing the total diabetes population by the total participants who attended the study. The prevalence rate was applied to the latest officially recorded total Maltese population demographic statistics to obtain the overall population with diabetes [12]. Similar calculations were used to estimate the prevalence rates of those with normal, overweight or obese status in the Maltese population $[14,15]$. Sensitive analyses based on the confidence intervals of the prevalence rates were preformed. The study only considered type 2 diabetes mellitus individuals. The Research Ethics Committee of the Faculty of Medicine and Surgery at the University of Malta together with the Information and Data protection commissioner gave their consent for this study.

The estimated cost burden for diabetes in Malta was calculated by applying the established prevalence rate of newly diagnosed diabetics and that for the previously known diabetics (individually) to the cost burden found in the literature for each diabetes subgroup. The cost burden for the newly diagnosed diabetics population was based on estimates performed by Zhang Y et al. (2009) 
in the USA after adjusting for the gross domestic poduct (GDP) per capita and by adjusting for deflation between the USA and Malta [16]. The cost burden for the previously known diabetes population was obtained from published International Diabetes Federation (IDF) data on Malta [17]. The cost attributed for the obese population was obtained from a study conducted in Malta by the Department of Health Information and Research in 2008, based on the 2008 European Health Information Survey, after $2 \%$ compound interest per annum was performed [18].

Projections to the year 2050 were performed by a bottom-up prevalence-based design for diabetes and for obese rates (1981 to 2014-2015 surveys). For purposes of comparative and statistical analysis, only the subgroup of adults between 25 and 64 years of age were utilized from SAHHTEK. This was required to keep a valid comparison with the 1981 study. By hypothesizing that no other factors distorted linear projections for both disease prevalence rates, an estimation of the affected population and their economic burden was established based on the EUROSTAT 2050 population projections for Malta [19]. Statistical analysis including chi squared was calculated by means of IBM SPSS version 21 . Demographic and lifestyle data was gathered by means of a combination of validated tools used during the "SAHHTEK" survey [20-22].

\section{Results}

The sample population that attended the study (response rate of $49 \% p=<0.05$ ) was weighted according to age, gender and locality. This enabled the data to be statistically representative of the whole population of Malta as well as to take in consideration the non-responders. After statistically weighting the sample, the final population dataset was of 3,947 (1998 males, 1949 females). Out of which, $10.39 \%$ (95\% CI: 9.47-11.38) suffered from diabetes, among which 6.31\% (95\% CI: 5.59-7.11) were previously known diabetics and 4.08\% (CI: 3.50 4.74 ) were newly diagnosed. $69.77 \%$ (95\% CI: $68.32-$ 71.18) of the total population was found to be either overweight or obese (Table 1) with a heavy male predominance. The diabetic population was predominantly either overweight or obese (92.20\% CI 95\%: 89.16-94.45) as seen in Table 1.

It was noted that younger ( $<55$ years) diabetics were predominately (54\% CI 95\%: 44.30-63.12\%) new (unknown) diabetics, while for those aged 55 and over, only 34\% (CI 95\%: 29.21-39.80) were new diabetics with the vast majority (66\% CI 95\%: 60.20-70.79) being known diabetics. This finding is in keeping with published data evaluating the degree of diabetes awareness between the 1981 and 2010 examination surveys conducted in Malta [23].

Further subdivision of the diabetic population by age and body weight revealed younger diabetics $(<55$ years) to be predominately obese (50\% CI $95 \%$ : $40.56-59.44)$ or overweight (46\% CI 95\%: 36.88-55.70), with only 4\% (CI 95\%: 2-8.9) having normal weight. Conversely, a higher proportion of older diabetics ( $\geq 55$ years) were found to belong to the normal weight category (9\% CI 95\%: 6.3712.50 ) with $57 \%$ (CI 95\%: 51.50-61.61) of these found

Table 1 BMI prevalence rates by population (diabetic and non-diabetic) population

\begin{tabular}{llll}
\hline BMl category & & & \\
\hline Total Population & Normal \% (95\% Cl) & Overweight \% (95\% Cl) & Obese \% (95\% Cl) \\
Total $(n=3947)$ & $30.26 \%(28.84-31.70)$ & $35.66 \%(34.17-37.15)$ & $34.11 \%(32.64-35.60)$ \\
Male $(n=1998)$ & $23.72 \%(21.91-25.64)$ & $39.39 \%(37.27-41.55)$ & $36.89 \%(34.80-39.03)$ \\
Female $(n=1949)$ & $36.94 \%(34.83-39.11)$ & $31.81 \%(29.79-33.91)$ & $31.25 \%(29.23-33.34)$ \\
$p$-value* & 0.0001 & 0.0001 & 0.0001 \\
& & & Obese \% (95\% Cl) \\
Diabetic Population & Normal \% (95\% Cl) & Overweight \% (95\% Cl) & $55.37 \%(50.53-60.11)$ \\
Total $(n=410)$ & $7.8 \%(5.55-10.84)$ & $36.83 \%(32.30-41.60)$ & $51.82 \%(45.92-57.57)$ \\
Male $(n=274)$ & $8.39 \%(5.61-12.33)$ & $39.78 \%(34.16-45.68)$ & $62.50 \%(54.12-70.19)$ \\
Female $(n=136)$ & $6.62 \%(3.36-12.26)$ & $30.88 \%(23.71-39.10)$ & 0.327 \\
$p$-value* & 0.73 & 0.84 & Obese \% (95\% Cl) \\
Non-Diabetic Population & & & $31.64 \%(30.12-33.19)$ \\
Total $(3537)$ & Normal \% (95\% Cl) & Overweight \% (95\% Cl) & $34.51 \%(32.31-36.79)$ \\
Male $(1724)$ & $32.85 \%(31.31-34.42)$ & $35.51 \%(33.76-36.90)$ & $28.9 \%(26.86-31.03)$ \\
Female $(n=1813)$ & $26.16 \%(24.14-28.29)$ & $39.33 \%(37.05-41.65)$ & 0.0001 \\
$p$-value* & $39.22 \%(36.99-41.48)$ & $31.88 \%(29.78-34.06)$ & 0.0001 \\
\hline
\end{tabular}

*Chi squared between each BMI category against gender 
obese and 34\% (CI 95\%: 28.59-39.13) found to be overweight $(p=0.001)$.

On incorporating the established prevalence rates and their corresponding confidence intervals from this study to the Maltese population, an estimate of the present total population burden of diabetes mellitus and obesity by 10-year age groups and gender was established [14]. Table 2 shows the estimated total Maltese diabetes population by gender and age.

In the Maltese adult population between 25 and 64 years of age, approximately 20,000 adults suffer from diabetes mellitus type 2. Out of which, approximately 10,000 adults suffer from diabetes and are yet unaware of it, with a male predominance (approx. 6,000). On comparing the Maltese diabetes population to the IDF Atlas ( $7^{\text {th }}$ Edition) European diabetes population, the Maltese diabetic population contributes to an approximate $0.03 \%$ of diabetes within Europe [2]. This prevalence percentage is an estimate comparison since the adult population age groups for the IDF (20 to 79 years) was different when compared to SAHHTEK study (25 to 64 years).

On the other hand, approximately 82,000 of the 233,136 adults (35\% of the adult population) in this age category (25-64 years) in Malta are obese, with a persisting male predominance (approx. 46,000) (Table 3). This ranks the Maltese population as the most obese country in the Mediterranean (Italy - 10.5\%; Cyprus 13.9\%; Greece - 16.9\%) and in Europe [24].

Estimating the cost burden (both direct and indirect) of an undiagnosed diabetic to be approximately $€ 1,052$ per person per year $(6.67 \%$ of the annual mean salary income per person in Malta), the annual burden for the entire population (25 to 64 years) was estimated at $€ 9,755,196(€ 7,065,232-€ 13,582,372)$, which contributes to $1.22 \%(0.88-1.70 \%)$ of the total health expenditure for Malta [16, 25]. The total health expenditure for Malta (for 2016) is approximately $€ 800,000,000$ [25]. The direct medical costs include hospital inpatient costs, physician care, emergency care, outpatients care and prescriptions, while the indirect costs included absence from work, reduced work performance and productivity [16]. Conversely, a known diabetic person's disease cost burden was approximately $€ 1,887$ per person annually $(11.96 \%$ of the annual mean salary income per person in Malta), attributing to an annual health burden of $€ 19,404,021$ $(€ 14,929,944-€ 25,336,749)$ for the entire population (25 to 64 years) [17]. This is consistent with $2.43 \%$ (1.87-

Table 2 Estimation of the diabetes mellitus population burden by applying the prevalence rates to Maltese population data by age and gender

\begin{tabular}{|c|c|c|c|c|}
\hline \multicolumn{5}{|c|}{ Maltese Population Diabetes Prevalence } \\
\hline Age & Total Maltese Population by age ${ }^{a}$ & Total (Cl) & Previously Known $(\mathrm{Cl})$ & Unknown Diabetics (Cl) \\
\hline $25-34$ & 62,180 & $404(143-964)$ & & $404(143-964)$ \\
\hline $35-44$ & 56,575 & $2,489(1,765-3,491)$ & $933(515-1,641)$ & $1,556(996-2,399)$ \\
\hline $45-54$ & 55,113 & $5,054(4,007-6,332)$ & $2,712(1,962-3,726)$ & $2,337(1,642-3,296)$ \\
\hline $55-64$ & 59,268 & $11,611(10,052-13,347)$ & $6,638(5,435-8,060)$ & $4,976(3,935-6,253)$ \\
\hline Total & 233,136 & $19,558(15,967-24,134)$ & $10,283(7,912-13,427)$ & $9,273(6,716-12,911)$ \\
\hline \multirow[t]{2}{*}{ Age } & \multirow[t]{2}{*}{ Male Maltese Population by age ${ }^{a}$} & \multicolumn{3}{|c|}{ Maltese Male Population Diabetes Prevalence } \\
\hline & & Total (Cl) & Previously Known $(\mathrm{Cl})$ & Unknown Diabetics (Cl) \\
\hline $25-34$ & 32,359 & & & \\
\hline $35-44$ & 29,143 & $1,781(1,195-2,611)$ & $667(332-1,271)$ & $1,113(664-1,821)$ \\
\hline $45-54$ & 27,728 & $4,204(3,252-5,368)$ & $2,426(1,708-3,397)$ & $1,777(1,173-2,651)$ \\
\hline $55-64$ & 29,585 & $6,935(5,784-8,236)$ & $3,763(2,896-4,840)$ & $3,172(2,379-4,189)$ \\
\hline Total & 118,815 & $12,920(10,231-16,216)$ & $6,856(4,937-9,507)$ & $6,062(4,216-8,661)$ \\
\hline \multirow[t]{2}{*}{ Age } & \multirow[t]{2}{*}{ Female Maltese Population by age ${ }^{a}$} & \multicolumn{3}{|c|}{ Maltese Female Population Diabetes Prevalence } \\
\hline & & Total (Cl) & Previously Known $(\mathrm{Cl})$ & Unknown Diabetics (Cl) \\
\hline $25-34$ & 29,821 & $397(143-945)$ & & $397(143-945)$ \\
\hline $35-44$ & 27,432 & $658(313-1,300)$ & $247(49-749)$ & $411(148-977)$ \\
\hline $45-54$ & 27,385 & $1,060(633-1,733)$ & $424(173-934)$ & $630(318-1,210)$ \\
\hline $55-64$ & 29,683 & $4,625(3,648-5,806)$ & $2,853(2087-3,856)$ & $1,772(1,178-2,624)$ \\
\hline Total & 114,321 & $6,740(4,736-9,785)$ & $3,524(2,309-5,539)$ & $3,210(1,787-5,756)$ \\
\hline
\end{tabular}


Table 3 Estimation of the obese population burden by applying the prevalence rates to Maltese population data by age and gender

\begin{tabular}{cll}
\hline \multicolumn{2}{l}{ Maltese Population } & \\
\hline Age & Total Maltese Population by age ${ }^{\mathrm{a}}$ & Obese BMI (CI) \\
$25-34$ & 62,180 & $15,968(14,127-17,951)$ \\
$35-44$ & 56,575 & $18,523(16,644-20,497)$ \\
$45-54$ & 55,113 & $22,315(20,386-24,299)$ \\
$55-64$ & 59,268 & $25,260(23,239-27,328)$ \\
Total & 233,136 & $82,066(74,397-90,076)$ \\
& & \\
Age & Male Maltese Population by age & Obese BMI (CI) \\
$25-34$ & 32,359 & $9,569(8,187-11,076)$ \\
$35-44$ & 29,143 & $12,310(10,914-13,750)$ \\
$45-54$ & 27,728 & $12,611(11,172-14,078)$ \\
$55-64$ & 29,585 & $11,730(10,349-13,171)$ \\
Total & 155,996 & $46,220(40,621-52,075)$ \\
Age & Female Maltese Population by age & \\
$25-34$ & 29,821 & Obese BMI (CI) \\
$35-44$ & 27,432 & $6,423(5,272-7,747)$ \\
$45-54$ & 27,385 & $5,914(4,792-7,212)$ \\
$55-64$ & 29,683 & $9,881(8,615-11,222)$ \\
Total & 114,321 & $13,568(12,111-15,052)$ \\
\hline
\end{tabular}

$\mathrm{Cl}-95 \%$ Confidence intervals

a2013 Malta Demographic Report

3.17\%) of the Maltese total health expenditure. Therefore the global cost burden of diabetes mellitus for the Maltese health system is approximate a total of $€ 29,159,217$ (€21,994,676-€38,919,121) annually. The diabetes cost burden contributes to $3.65 \%$ (2.79-4.87\%) of the total health expenditure (state and private expenditure) for Malta [25]. On the other hand, the attributed cost burden (included inpatient stay, day patient stay, general practitioner and specialist consultations but not medication and surgical procedures) for obesity in Malta ( $2 \%$ compound interest per annum), was estimated to be $€ 23,732,781$ ( $€ 21,514,972-€ 26,049,204)$ for the year 2016 [18]. The obesity cost burden contributes to $2.97 \%$
(2.69-3.26\%) of the total health expenditure for Malta [25]. Therefore the total 'diabesity' cost burden for Malta, in 2016, is an approximate total of $€ 52,891,998$ $(€ 43,509,648-€ 64,968,325)$ which amounts to $6.61 \%$ (5.44-8.12\%) of the Malta's total health expenditure.

The projected EUROSTAT 2050 Maltese population (25 to 64 years) was incorporated within the projected prevalence rates for diabetes and obesity rates as seen in Table 4 . On incorporating these projected prevalence rates within the projected cost burden ( $2 \%$ compound interest per annum from the 2016 costs) for diabetes and obesity, we were able to estimate the likely economic burden caused by these diseases for 2050 (Table 5). The total adult population (25 to 64 years) projected for 2050 appears to decrease from the current 2016 adult population. Meanwhile, the diabetes and obese population will increase by approximately 28 and $15 \%$ respectively by 2050 . The economic burden is expected to increase in association with this disease burden. An exponentiation of 1.2 in the diabetes cost burden and exponentiation of 2 in obese cost burden from the current (2016) is expected to occur by 2050 . This contributes to an estimated cost burden of $€ 33,751,487$ (€25,458,606$€ 45,048,473)$ for diabetes mellitus and $€ 46,532,294$ $(€ 42,183,889-€ 51,074,049)$ for the obese. Therefore the estimated total cost burden for 2050 for diabetes mellitus type 2 and obesity would amount to one-eight of the current (2016) total health expenditure $(€ 800,000,000)$.

\section{Discussion}

Diabetes mellitus type 2 and obesity prevalence rates are on the rise with the majority of diabetic patients being obese [26]. This is observed in the current study where the bulk of the Maltese population was either overweight or obese. Apart from this, a tenth of the total adult population (18 to 70 years) suffered from diabetes mellitus type 2 . Another worrying feature is that the majority of the Maltese diabetic population was obese. The projected Maltese estimates for 2050, also exhibit an exponential increase in the obese population, along with a drastic increase in diabetes mellitus. Although diabetes might not develop in all those who are obese, the accumulation of adipose tissue initiates a cascade of

Table 4 Projected prevalence rates of diabetes and obese population for 2050 in Malta

\begin{tabular}{llll}
\hline Age & \multicolumn{2}{l}{$\begin{array}{l}\text { 2050 Projected Total Maltese } \\
\text { Population by age }\end{array}$} & \multicolumn{2}{l}{ Projected Diabetes \& Obesity Prevalence for 2050 } \\
\hline 25-34 & 56,709 & $601(255-913)$ & Obese (Cl) \\
$35-44$ & 52,965 & $3,813(2,961-4,610(19,791-23,829)$ & $21,175(19,650-22,685)$ \\
$45-54$ & 53,819 & $5,457(4,698-6,211)$ & $22,970(21,361-24,579)$ \\
$55-64$ & 62,342 & $15,199(14,014-16,153)$ & $28,079(26,882-29,295)$ \\
Total & 225,835 & $25,071(21,929-27,943)$ & $94,034(87,684-100,388)$ \\
\hline
\end{tabular}

$\mathrm{Cl}$ - 95\% Confidence interval

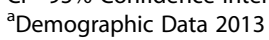


Table 5 Comparison of the total cost burden for diabetes and obese population for 2016 and those projected for 2050

\begin{tabular}{lll}
\hline Maltese Population (25 to 64 years) & & \\
\hline \\
2016 Costs & Total Diabetes & Obese \\
& $€ 29,159,217$ & $€ 23,732,781$ \\
2050 Projected Costs with 2\% Compound interest per annum & $(€ 21,994,676-€ 38,919,121)$ & $(€ 21,514,972-€ 26,049,204)$ \\
& $€ 33,751,487$ & $€ 46,532,294$ \\
& $(€ 25,458,606-€ 45,048,473)$ & $(€ 42,183,889-€ 51,074,049)$ \\
\hline
\end{tabular}

metabolic events. These in turn have the ability to initiate or exacerbate insulin resistance in those more predisposed. All this can subsequently lead to the development of various metabolic diseases including hypertension, dyslipideamia and cardiovascular disease [27].

Tackling the obesity epidemic in its own right is of utmost importance in order to prevent further obesityrelated illnesses that are contributing not only to a decrease in the quality of life and mortality of many, but also attributing to an estimated 8 to $10 \%$ of the total health expenditure in many European countries [28]. In Malta, the cost burden attributed to overweightobesity was estimated to be $5.7 \%$ of total health expenditure in 2008 [18]. Considering that only the obesity burden was evaluated in the current study, one cannot directly compare to the 2008 (Malta) health expenditure. However, no drastic exponential increase appears to have occurred. On comparing the current obesity impact on the total health expenditure to other European countries, Malta relates well to the obesity related expenditure reported [28].

The International Diabetes Federation estimated the 2009 cost burden for diabetes mellitus to contribute to $11 \%$ of the total health expenditure in Malta [29]. Our results showed that diabetes (direct and indirect) cost burden on the total health expenditure has decreased by approximately three-fold from the IDF estimate for Malta. According to the IDF, diabetes mellitus type 2 accounts for 5 to $20 \%$ of the majority of the countries' total health care expenditure, which is in keeping to the study's results [2]. In Malta, diabetes appears to have the same burden effect on the total health care expenditure as other countries.

The diabetes and obesity epidemics present as a great burden of care and an economic challenge to the Maltese population from the relatively young age of 35 years onwards [30]. In fact, extrapolations from the current (2016) obese and diabetes burden to 2050, exhibit a major health care concern for Malta, especially with the expected high diabetes prevalence rise and related economical costs. It is questionable whether the overall health budget will also swell proportionately, given the current economic situation. This is more so considering that by 2050, diabetes and obesity health burdens are expected to amount to one-eight of the current (2016) total health care expenditure. The planned Malta EU Presidency for 2017 (January to June) reflects the obesity burden and is planned to tackle Childhood obesity. Considering that a substantial proportion of the young population ( $<55$ years) was found to have unknown diabetics and an increased body weight (obese > overweight), this brings forward the need for immediate action. The higher the obesity and diabetes prevalence rates, the higher the expected hospitalization rates and other related costs [5]. It is well established that the risk of co-morbidity increases with the increase in body mass index (BMI) [31]. Per capita costs reach their maximum among the obese population [32]. This phenomenon has been recorded in various European countries [33-35]. It is essential that health services in Malta and elsewhere in Europe embark on effective preventive strategies and opportunistic screening to target these conditions from an early age, before the disease has been ingrained for too long [23]. Although this could impose an even larger health budget request on the country, such early action could help decrease the health burden contributed to diabetes, obesity and their associated complications. In fact, disease prevention should always be the primary target of any health management strategy.

\section{Study limitations}

The response rate obtained was $49 \%$. This can present as a potential non-response bias but the data was statistically weighted according to age, gender and locality in order to overcome this potential bias. The study does not cover the whole population but only a subset of the adult population. Since the prevalence of diabetes is substantial within the elderly population, costs may be affected by other underlying comorbidities. General demographic data was based on the latest published reports from 2013. The health cost for undiagnosed diabetes was based on a U.S. study, as no data was available for the Maltese population, although the GPD per capita for both countries was taken in consideration. The cost of illness data was obtained from secondary sources and this may affect the validity of the cost of illness in the Maltese health care setting. The previously known diabetes cost was obtained from the 2015 IDF estimated costs for Malta but no detailed description was available to the health care costs constitution. All costs from the 
secondary sources lacked confidence intervals; therefore sensitivity analysis could not be performed on the unit costs. Comparisons with other studies were difficult due to the fact that the age groups and the total population samples were different from the current study and not comparable. Projections for the year 2050 were based on current conditions with an assumption that all demographic and risk factors would continue at their current rates. The economical burden excluded society burden including intangibles from pain and decreased quality of life, as well as the impact on caregivers.

\section{Conclusion}

The study explored the present disease burden and economic costs for diabetes and obesity in Malta as well as those projected for 2050. A substantial prevalence and economical burden increase was estimated for 2050. The current Maltese health care expenditure for both diseases was similar to other European countries estimates. The data obtained should encourage policy makers to further explore the situation and bring forward preventative strategies considering the present 'diabesity' burden and the expected exponential increase. Implementing early screening tests for diabetes and obesity might be one of the best strategies to counteract the epidemic and reduce the overall costs.

\section{Abbreviations}

BMI: Body mass index; GDP: Gross domestic product; IDF: International diabetes federation; WHO: World Health Organization

\section{Acknowledgements}

The authors are extremely grateful for the strong support forthcoming from the University of Malta (through the Medical School and Research Innovative Development Trust department) and from the Alfred Mizzi Foundation as major sponsors, as well as that of a host of others, including Atlas Health Insurance (Malta). The in-kind support and encouragement of the Parliamentary Secretariat for Health of the Government of Malta is also gratefully acknowledged.

\section{Funding}

Funding was obtained from the University of Malta, Alfred Mizzi Foundation and Atlas Insurance (Malta). Funding had no role in the design of the study, analysis, and interpretation of data and in writing the manuscript.

\section{Availability of data and materials}

Data analysed during this study are included in this published article. More detailed datasets analysed during the current study available from the corresponding author on reasonable request.

\section{Authors' contributions}

SC, JV, NC, NP and JM were responsible for the design of the cross-sectional protocol. These authors were also involved in the writing and reviewing of the article. SC, JA, BA, FA and EZ were the fieldworkers and data collectors of the cross-sectional study. These also contributed to formulation of the article. All authors read and approved the final manuscript.

\section{Competing interests}

The authors declare that they have no conflict of interest. The funding body had no influence on the protocol of the survey or on the data analysis. No author received any personal funding.

\section{Consent for publication}

Not applicable.

\section{Ethics approval and consent to participate}

All procedures performed in studies involving human participants were in accordance with the ethical standards of the institutional and/or national research committee and with the 1964 Helsinki declaration and its later amendments or comparable ethical standards. Ethics approval was granted from Research Ethics Committee of the Faculty of Medicine and Surgery at the University of Malta. Every participant gave his or her informed consent.

\section{Author details}

${ }^{1}$ Department of Anatomy, Faculty of Medicine and Surgery, Biomedical Building, University of Malta, Msida MSD 2080, Malta. ${ }^{2}$ Faculty of Medicine and Surgery, University of Malta, Msida, Malta. ${ }^{3}$ Department of Public Health, Faculty of Medicine and Surgery, University of Malta, Msida, Malta. ${ }^{4}$ Faculty of Dental Surgery, University of Malta, Msida, Malta. ${ }^{5}$ Mater Dei Hospital, Msida, Malta.

Received: 10 September 2016 Accepted: 9 November 2016

Published online: 12 December 2016

\section{References}

1. Seidell JC, Halberstadt J. The global burden of obesity and the challenges of prevention. Ann Nutr Metab. 2015;66 suppl 2:7-12.

2. International Diabetes Federation. IDF Diabetes Atlas, $7^{\text {th }}$ edn. Brussels: International Diabetes Federation; 2015.

3. Webber L, Divajeva D, Marsh T, McPherson K, Brown M, Galea G, Breda J. The future burden of obesity-related diseases in the 53 WHO Europeanregion countries and the impact of effective interventions: a modeling study. BMJ Open. 2014;4:e004787.

4. Lean M. Health Consequences of overweight and obesity in adults. Obesity Epidemiology From Aetiology to Public Health. Oxford: Oxford University Press second edition. 2010. p. 43-57.

5. Wang YC, McPherson K, Marsh T, Gortmaker SL, Brown M. Health and economic burden of the projected obesity trends in the USA and the UK. Lancet. 2011;378:815-25.

6. De Berardis G, D'Ettorre A, Graziano G, Lucisano G, Pellegrini F, Cammarota $S$, et al. The burden of hospitalization related to diabetes mellitus: a population-based study. Nutr Metab Cardiovasc Dis. 2012;22:605-12.

7. Dall TM, Zhang Y, Chen YJ, Quick WW, Yang WG, Fogli J. The economic burden of diabetes. Health Aff (Millwood). 2010;29:297-303.

8. Cuschieri S, Mamo J. Malta: Mediterranean diabetes hub - a journey through the years. MMJ. 2014;26(3):27-31.

9. Katona G, Aganovic I, Vuskan V et al. National diabetes programme in Malta: Phase I and II Final Report. Geneva: World Health Organization;1983.

10. Research Department of Health Information. European Health Examination Survey 2010- Pilot Study. Gwardamangia: Ministry of Health, the Elderly and Community Care Malta; 2010.

11. Cuschieri S, Mamo J. Diabetes type 2 prevalence in Malta. An update and more. Synapse. 2015;14(2):11.

12. World Health Organization. Obesity and Overweight Fact Sheet. World Health Organization Geneva 2016. Available: http://www.who.int/ mediacentre/factsheets/fs311/en/.

13. American Diabetes Association. Classification and diagnosis of diabetes. Diabetes Care. 2016;39(Suppl1):S13-22.

14. National Statistics Office. Demographic Review 2013. Valletta: National Statistics Office; 2015.

15. World Health Organization. Obesity: preventing and managing the global epidemic. Report of a WHO consultation. Geneva: World Health Organization; 2000.

16. Zhang Y, Dall T, Mann SE, Chen Y, Martin J, Moore V, et al. The economic cost of undiagnosed diabetes. Popul Health Manag. 2009;12:95-101.

17. International Diabetes Federation, Malta: http://www.idf.org/membership/ eur/malta Accessed 2nd May 2016.

18. Calleja N, Gauci D. The cost of obesity. In: The 7th Malta Medical School Conference. Department of Health Information and Research, Ministry of Social Policy, Malta: The 7th Malta Medical School Conference, 2009.

19. EUROSTAT: http://ec.europa.eu/eurostat Accessed 23th May 2016

20. European Commission EUROSTAT and Department of Health Information and Research. European health interview survey (EHIS) questionnaire. 2008.

21. Bjerregaard $P$, Becker $U$. Validation of survey information on smoking and alcohol consumption against import statistics, Greenland 1993-2010. IJCH. 2013;72:203-14 
22. Tolonen $\mathrm{H}$ (Ed.) EHES Manual. Part B. Fieldwork procedures. National Institute for Health and Welfare, 2013. http://urn.fi/URN:ISBN:978-952-245843-8. Accessed 1 Aug 2014.

23. Sammut A, Calleja N, Cachia J. Investing in the health of the 41-60 year old: reaping the return in the 60+ population? Malta Med J. 2016;28(01):12-8.

24. EUROSTAT (2016) Body mass index (BMI) by sex, age and educational attainment level. Available: http://ec.europa.eu/eurostat/data/database [Accessed 4 Nov 2016].

25. Index Mundi. Malta - Health expenditure. Available: http://www. indexmundi.com/facts/malta/health-expenditure [Accessed 4th Nov 2016]

26. Eckel RH, Kahn SE, Ferrannini E, Goldfine AB, Nathan DM, Schwartz MW, et al. Obesity and type 2 diabetes: what can be unified and what needs to be individualized? Diabetes Care. 2011;34:1424-30.

27. Cali AMG, Caprio S. Prediabetes and type 2 diabetes in youth: an emerging epidemic disease? current opinion in endocrinology. Diabetes Obes. 2008; 15:123-7.

28. Brandt L, Erixon F. The prevalence and growth of obesity and obesity related illnesses in Europe. Geneva: European Center for International Political Economy (ECIPE); 2013.

29. Zhang P, Zhang X, Brown JB, Vistisen D, Sicree RA, Shaw J, Nichols GA. Economic impact of diabetes. International diabetes federation diabetes atlas fourth edition. 2009.

30. World Health Organization. Global Report on Diabetes. Geneva: World Health Organization; 2016.

31. Van den Bos GAM. The burden of chronic diseases in terms of disability, use of health care and healthy life expectancies. Eur J Pub Health. 1995;5:29-34.

32. Dee A, Kearns K, O'Neill C, Sharp L, Staines A, O'Dwyer V, et al. The direcr and indirect costs of both overweight and obesity: a systemic review. BMC Res Notes. 2014;7:242.

33. Borg S, Persson U, Odegaard K, Berglund G, Nilsson PM. Obesity, survival and hospital costs - findings from a screening project in Sweden. Value Health. 2005;8(5):562-71.

34. Konnopka A, Bodemann M, Konig HH. Health burden and costs of obesity and overweight in Germany. Eur J Health Econ. 2011;12:345-52.

35. Schmid A, Schneider H, Golay A, Keller U. Economic burden of obesity and its comorbidities in Switzerland. Soc Prev Med. 2004;50(2):87-94.

\section{Submit your next manuscript to BioMed Central and we will help you at every step:}

- We accept pre-submission inquiries

- Our selector tool helps you to find the most relevant journal

- We provide round the clock customer support

- Convenient online submission

- Thorough peer review

- Inclusion in PubMed and all major indexing services

- Maximum visibility for your research

Submit your manuscript at www.biomedcentral.com/submit

) Biomed Central 